\title{
New techniques for wine aging
}

\author{
Hatice Kalkan Yıldırım and Ezgi Dündar \\ Ege University, Department of Food Engineering, 35100 Bornova, Izmir, Turkey
}

\begin{abstract}
The aging of wine requires a long time therefore it can cause loss of time and money. Therefore using of new techniques for wine aging shortens the length of aging time and wines may be placed on the market more quickly. Nowadays, gamma irradiation, ultrasonic waves, AC electric field and microoxygenation are the new techniques for wine aging. Gamma irradiation (after fermentation) is accelerated physical maturation method. Gamma irradiation, in a suitable dosage ( $200 \mathrm{~Gy}$ ), is a suitable method for improving some wine defects and producing a higher taste quality in wine. The $20 \mathrm{kHz}$ ultrasonic waves aged wine much more quickly than standard aging, with similar quality. The wine treated by $20 \mathrm{kHz}$ ultrasonic waves had a taste equivalent to 1 year aged wine. Wine maturing with $\mathrm{AC}$ electric field promises novel process accelerating aging process of fresh wine when suitable conditions are applied. As a result of research, an optimum treatment (electric field $600 \mathrm{~V} / \mathrm{cm}$ and duration time $3 \mathrm{~min}$ ) was identified to accelerate wine aging. Harsh and pungent raw wine become harmonious and dainty. This process is equivalent to 6 month aging in oak barrel. Microoxygenation is a very important technique used in aging wines in order to improve their characteristics. The techniques of wine tank aging imply the use of small doses of oxygen $\left(2 \mathrm{ml} \mathrm{L}^{-1} \mathrm{month}^{-1}\right)$ and the addition of wood pieces of oak to the wine. Studies concerning these new techniques demonstrated that maturation of wines become more quickly than standard maturation procedures with keeping and improving the wine quality.
\end{abstract}

\section{Wine aging}

The term "wine aging" included group of reactions occurring after bottling of wines. The "wine maturation" is related to steps of wine storage before bottling [1,2]. The wine maturation can last from 6 to 24 months or many years. At this stage, clarification may be applied taking into account the possibility that the wine will undergo malolactic fermentation. Wine aging process starts with bottling of wine and is also referred to as also reductive aging since aging is carried out without oxygen [3].

During wine aging many reactions occurred that caused significant organoleptical changes in wines. During the process of maturation and aging, the most obvious change occurs in the color of the wine which refers to phenols changes.

The phenolic compounds present in the wines are divided into two groups, flavonoids and phenolic compounds other than flavonoids (Fig. 1). Phenolic compounds containing a hydroxyl (- $\mathrm{OH})$ group attached to a benzene ring in their structure are present in cells forming part of the grape such as shell, nucleus and stem. Flavonoids are in the C6-C3-C6 diphenylpropane structure and the triple carbon bridge between the phenyl groups forms a ring with oxygen. Differences among flavonoids are due to the number of hydroxyl groups attached, the degree of unsaturation and the oxidation level of the triple carbon segment [4].

The changes occurring in the phenols in wines during and after the production are realized by the following mechanisms [5].
1. The destruction of anthocyanins;

2. Reactions of tannins with proteins; Reactions of tannins with polysaccharides;

3. Cation formation of procyanidines;

4. Oxidation reactions of procyanidins;

5. Polymerization reactions of procyanidins;

6. Copigment formation processes of anthocyanins;

7. Reaction of anthocyanins with compounds containing polarized double bonds;

8. Condensation reactions of anthocyanins with tannins;

In the case of young wines "aging" is expected to protect organoleptic properties for long time. In the aging of wines, it is intended to make a specific change in the composition of the wine by changing the organoleptic properties of the wine [2].

Wine aging requires a long time therefore it can cause loss of time and money. Using of new techniques for wine aging by providing high quality wines, could shortens the length of aging time and allow wines be placed on the market more quickly.

\section{Wine aging in oak barrels}

The oak which used in the time of the ancient Romans, is used for making barrels nowadays, also. Today, oak barrels are used for the wine aging. Oxidation which takes place in a small amount over time in the barrel, allows the wine to produce a variety of unique aromas in the stage of aging [3]. Controversies to this, there are some disadvantages of oak barrels used as traditional 


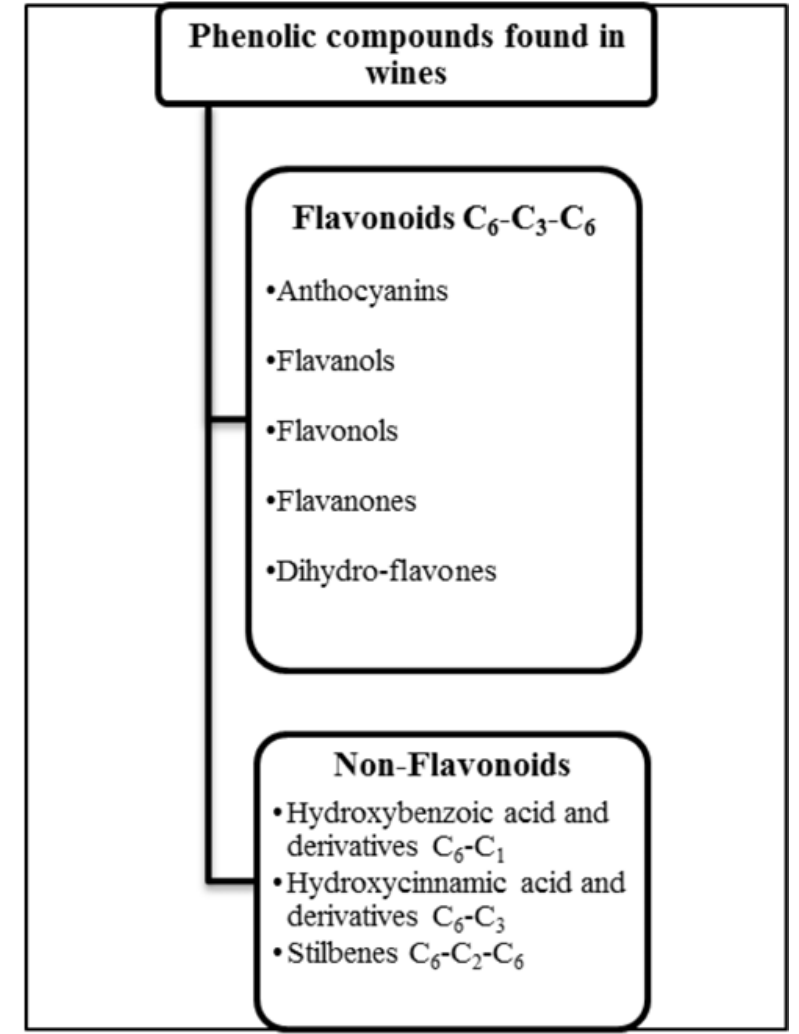

Figure 1. Phenolic compounds found in wines.

aging methods. The aging of wine continues long time so it causes time loss. Additionally, due to the undesired microorganisms such as Brettanomyces and Dekkera species which may contaminate wine barrel must be renewed over time [6].

Considering all these disadvantages, current studies have focused on new techniques for wine aging which will be an alternative to aging with the barrel that shortens the aging period and the preservation of quality after aging of the wine [6]. These techniques include the use of some physical applications and micro-oxygenation applications of wines. Each technique can contribute to different points for the process of aging the wines [7]. Ultrasonic waves, electric field, gamma irradiation, applications can be used in the aging of wines. In studies conducted using these methods, it is aimed to shorten the period of aging of wine and to offer high quality wines to consumers [7].

\section{Physical methods in wine aging}

\subsection{Ultrasonic waves}

The aging process for wines using ultrasound technique is a specific example of ultrasonically developing oxidation [8]. The aging effect of ultrasonic treatment is related to the cavitation created by ultrasonic waves and the growing and collapse of micro sized bubbles. Ultrasonic waves can precipitate these bubbles therefore temperature and pressure may rise. High pressure and temperature can influence the wine aging and the wine could be negatively affected. However, controlled ultrasonic waves can positively affect the chemical reactions in the wine [9].

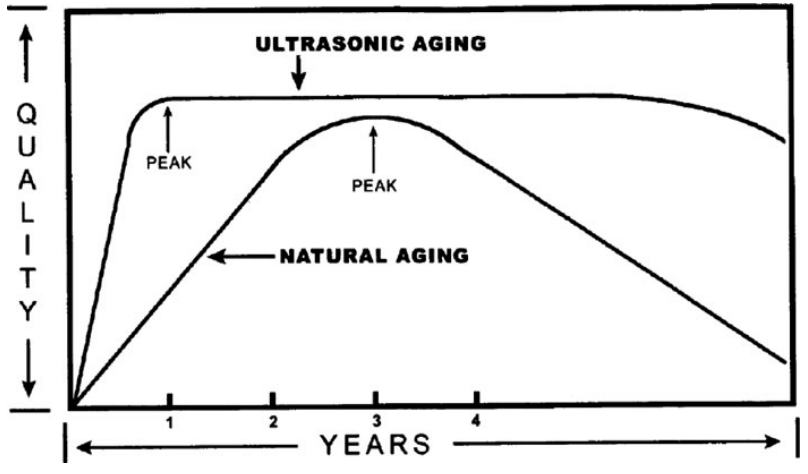

Figure 2. Comparison of qualities in natural aging in wine and ultrasonic aging in wine (adapted from Leonhardt and Morabito, 2007).

The wines reach the 'peak' points after being aged for a certain period of time. The wines are the most fine at the peak points and the changes that occur in the tannins so wine have soft flavor and a complex bouquet [10]. After that point, the quality of the wine starts decreasing, so it is best to consume the wines when they reach their peak. After the application of the ultrasonic waves, the wines can reach their peak quickly, and the wines can retain their peak points and qualities for a longer time than the standard aging process. This relationship has been shown as Fig. 2. Peak points in wines have a very important place in the extension of shelf life [11].

In a study, wines made by using rice and corn were subjected to $20 \mathrm{kHz}$ ultrasonic wave application for one week with purpose of acceleration of wine aging. Concerning rice wines, the $20 \mathrm{kHz}$ ultrasound application allowed the production of wines with the same quality as the standardized aging wines, but in case of corn wine the same quality was not obtained [12] Similar results, related to the differences of used grapes and ultrasound treatment parameters were also determined [13].

\subsection{Electric field}

Electric field applications cause electroporation of cell membranes. As a result, diffusion of soluble materials and microbial inactivation are increasing [14]. It was determined that the application of pulsed electric field in red wines before oak barrels aging could positively affected the aging process time: the extraction efficiency of polyphenolic compounds could increase and high quality wine could be produced [6].

There is an another study creating an innovative technique to implement on an pilot scale implementing AC electric field to speed up the aging of Cabernet Sauvignon wines. Electricity application of $600 \mathrm{~V} / \mathrm{cm}-$ 3 min ensures that harsh and pungent wines become harmonious and dainty wines. The results demonstrated that high alcohol and aldehyde content decreased and the number of ester and free amino acids increased slightly in the samples treated with electric field. Thus, the highvoltage electric field could be an alternative for wine aging acceleration for production of wine with high quality [15]. Even this result and similar ones $[16,17]$ the need of more studies are required concerning the clarification of treatment parameters for wines produced from different grape varieties. 


\subsection{Gamma irradiation}

Gamma radiation is one of the three types of natural radioactivity. The other two types of natural radioactivity are alpha and beta radiation, which are in the form of particles. Gamma rays are the most energetic form of electromagnetic radiation, with a very short wavelength of less than one-tenth of a nanometer [18].

The basic technique for its application in foods is to expose to gamma rays at determined conditions [19]. The effects concerning wine is related to accelerating physical maturation.

In a previous study, gamma radiation was applied after fermentation to mature rice wines. Gamma irradiation, in a suitable dosage $(200 \mathrm{~Gy})$, is a suitable method for improving some wine defects and producing a higher taste quality in wine, without the presence of irradiation residues [20]. However, more work needs to be done to understand the effects of gamma irradiation on human health [5].

\section{Chemical methods in wine aging}

\subsection{Micro-oxygenation}

Microoxygenation works by the addition of oxygen into red wine at a controlled rate and flow to stabilize color and improve astringency and aromatic components of the final wine [21].

It is well known that adding oxygen to wines affects chemical and sensory components of a wine by changing forms of phenolics, sulfur compounds and other reactions related to these compounds. The amounts of used oxygen is of critical importance. In case of too much oxygen, several problems can occur, including the oxygenation of phenolic compounds, increases in astringency, color, mouthfeel, and bacteria populations.

In a study, wines were aged for three months in "new" American oak barrels, "old" American oak barrels and treated with microoxygenation method for three months. Results demonstrated that microoxygenation could improve wine color, phenolic and chromatic characters in similar manner to oak barrels application [22].

Since this technique is used with a lot of purposes as improving the organoleptic properties of the stability of the wine color, reduction of the sulfur-derived smells and to simulating the wine aging $[5,23]$ before application of microoxygenation optimum conditions for wine category, each grape varieties be determined.

\section{Concluding remarks}

Modern winemaking has discovered many different techniques and technologies to improve upon the quality of wine. Although the traditional method used in years is regarded as creating quality wines, it has been sought for new methods. Using of new techniques for wine aging could shortens the length of aging time and wines may be placed on the market more quickly. More research work is needed to make a definite comment on ultrasonic, electric field and gamma irradiation applications used as an alternative to traditional wine aging. Microoxygenation application is an improved method and it may be recommended to use it in combination with other aging methods.

\section{References}

[1] A.L. Waterhouse, G.L. Sacks, D.W. Jeffery Understanding wine chemistry. (John Wiley \& Sons, 2016)

[2] J. Morena, R. Peinado. Enological chemistry. (Academic Press, 2012)

[3] R.S. Jackson, Wine science: principles and applications. (Academic press, 2008)

[4] F. Cuyckens, M. Claeys, Mass spectrometry in the structural analysis of flavonoids, Journal of Mass Spectrometry 39, 1-15 (2004)

[5] P. Ribéreau-Gayon, D. Dubourdieu, B. Donèche, A. Lonvaud, (Eds.) Handbook of enology, the microbiology of wine and vinifications (Vol. 1). (John Wiley \& Sons, 2006)

[6] F.G. Martín, D.W. Sun, Ultrasound and electric fields as novel techniques for assisting the wine ageing process: The state-of-the-art research. Trends in Food Science and Technology 33, 40-53 (2013)

[7] Y. Tao, J.F. Garcia, D.W. Sun, Advances in wine aging technologies for enhancing wine quality and accelerating wine aging process, Critical Reviews in Food Science and Nutrition 54, 817-835 (2014)

[8] T. Mason, Power ultrasound in food processingthe way, Ultrasound in Food Processing, 105 (1998)

[9] A.J. Saterlay, R.G. Compton, Sonoelectroanalysisan overview, Fresenius' Journal of Analytical Chemistry 367, 308-313 (2000)

[10] J. Robinson, J. Harding, The Oxford Companion to Wine. (American Chemical Society, 2015)

[11] C.G. Leonhardt, J.A. Morabito, Wine aging method and system, US Patent 11/043,121 (2007)

[12] A.C. Chang, F.C. Chen, The application of $20 \mathrm{kHz}$ ultrasonic waves to accelerate the aging of different wines. Food Chemistry 79, 501-506 (2002)

[13] Y. Tao, Z. Zhang, D. Sun, Experimental and modeling studies of ultrasound-assisted release of phenolics from oak chips into model wine, Ultrasonics Sonochemistry 21, 1839-1848 (2014)

[14] L. Picart, J.C. Chetfel, Pulsed electric fields. Food preservation techniques. Fla.: CRC Press. 57-68 (2003)

[15] A.X. Zeng, S.J Yu, L. Zhang, X.D Chen, The effects of AC electric field on wine maturation, Innovative Food Science and Emerging Technologies 9, 463-468 (2008)

[16] Z. Lin, X. Zeng, S. Yu, D. Sun, Enhancement of Ethanol-acetic acid esterification under room temperature and non-catalytic condition via pulsed electric field application, Food And Bioprocess Technology 5, 2637-2645 (2011)

[17] B. Zhang, X. Zeng, D. Sun, S. Yu, M. Yang, S. Ma, Effect of Electric Field Treatments on Brandy Aging in Oak Barrels, Food And Bioprocess Technology, 6, 1635-1643 (2012)

[18] Gamma Radiation. [online] Available at: https://www.ndeed.org/EducationResources/ 
CommunityCollege/Radiography/Physics/ gamma.htm [Accessed 22 Apr. 2017]

[19] J.M. Wetheril, Gamma Irradiation of Food, Canadian Journal of Public Health/Revue Canadienne de Sante'e Publique 56, 521-524 (1965)

[20] A.C. Chang, The effects of gamma irradiation on rice wine maturation, Food Chemistry 83, 323-327 (2003)

[21] The Effect of Micro-Oxygenation on Wine Quality and Consumer Preferences. [online] Available at: http://www . academicwino.com/2013/01/ microoxygenation-quality-preferences . html/ [Accessed 22 Apr. 2017]

[22] M. Cano- López, J.M. López, F. Pardo-Mínguez, E. Gómez-Plaza, Oak barrel maturation vs. microoxygenation: Effect on the formation of anthocyaninderived pigments and wine colour, Food chemistry 119, 191-195 (2010)

[23] E. Gómez-Plaza, M. Cano-López,A review on microoxygenation of red wines: Claims, benefits and the underlying chemistry. Food Chemistry 125, 1131-1140 (2011) 